\title{
Registro Español de Trasplante Cardiaco. XXIX Informe Oficial de la Sección de Insuficiencia Cardiaca de la Sociedad Española de Cardiología (1984-2017)
}

Spanish Heart Transplant Registry. 29th Official Report of the Spanish Society of Cardiology Working Group on Heart Failure

Francisco González-Vílchez ${ }^{\mathrm{a}}$, Luis Almenar-Bonet ${ }^{\mathrm{b}}$, María G. Crespo-Leiro ${ }^{\mathrm{c}}$, Luis Alonso-Pulpón ${ }^{\mathrm{d}}$, José González-Costelo ${ }^{\mathrm{e}}$, José Manuel Sobrino-Márquez ${ }^{\mathrm{f}}$, José María Arizón del Prado ${ }^{\mathrm{g}}$, Iago Sousa-Casasnovas ${ }^{\mathrm{h}}$, Juan Delgado-Jiménez ${ }^{\mathrm{i}}$, Félix Pérez-Villa ${ }^{j}$ en representación de los Equipos Españoles de Trasplante Cardiaco

\footnotetext{
${ }^{a}$ Hospital Universitario Marqués de Valdecilla, Santander, Cantabria, España

${ }^{b}$ Hospital Universitario y Politécnico La Fe, Valencia, España

${ }^{c}$ Complexo Hospitalario Universitario A Coruña, A Coruña, España

${ }^{d}$ Hospital Universitario Puerta de Hierro-Majadahonda, Majadahonda, Madrid, España

${ }^{e}$ Hospital Universitari de Bellvitge, L'Hospitalet de Llobregat, Barcelona, España

${ }^{f}$ Hospital Universitario Virgen del Rocío, Sevilla, España

${ }^{g}$ Hospital Universitario Reina Sofía, Córdoba, España

${ }^{h}$ Hospital Universitario Gregorio Marañón, Madrid, España

${ }^{i}$ Hospital Universitario 12 de Octubre, Madrid, España

${ }^{j}$ Hospital Universitari Clínic de Barcelona, Barcelona, España
} 


\title{
Resumen
}

Introducción y objetivos. Se actualizan las características clínicas y los resultados de los trasplantes cardiacos realizados en España en el periodo 2008-2017.

Métodos. Se describen las características de los receptores, los donantes, los procedimientos quirúrgicos y los resultados de los trasplantes realizados en 2017 y se ponen en contexto respecto a los del periodo 2008-2016. Resultados. En 2017 se realizaron 304 trasplantes. Desde 1984, se han realizado 8.173 trasplantes, 2.689 de ellos desde 2008. Para el periodo 2008-2017, se observan tendencias temporales significativas en las características del receptor (menores resistencias vasculares pulmonares, menos ventilación mecánica previa al trasplante, mayor tasa de diabéticos y cirugía cardiaca previa), el donante (de más edad, más donantes mujeres y más donantes con parada cardiaca) y el procedimiento (menos tiempo de isquemia). En 2017, el $27 \%$ de los trasplantes se realizaron previa asistencia ventricular mecánica ( $\mathrm{p}<0,001$ para la tendencia). En la última década, se observa una tendencia a una mejor supervivencia.

Conclusiones. La actividad de trasplante cardiaco se estabiliza en alrededor de 300 procedimientos al año. Se extiende el uso de dispositivos de asistencia ventricular antes del trasplante, con tendencia a la mejora de la supervivencia.

\begin{abstract}
Introducción y objetivos. The present report updates the characteristics and results of heart transplantation in Spain, mainly focused in the 2008-2017 period.

Methods. We describe the recipient and donor characteristics, surgical procedures, and outcomes of heart transplants performed in 2017. The 2017 data were compared with those obtained from 2008 to 2016.

Results. A total of 304 cardiac transplants were performed in 2017. Between 1984 and 2017, 8173 procedures were performed, 2689 of them after 2008. Significant temporal trends were observed in recipient characteristics (lower pulmonary vascular resistance, lower use of mechanical ventilation, and a higher percentage of diabetic patients and those with previous cardiac surgery), donor characteristics (older donor age and a higher percentage of female donors and those with a prior cardiac arrest) and procedures (lower ischemia time). In 2017, 27\% of patients were transplanted after undergoing mechanical ventricular assistance $(P<.001$ for trend). In the last decade, there was a trend to better survival.

Conclusions. Around 300 transplants per year were performed in Spain in the last decade. There was a significant increase in the use of pretransplant mechanical circulatory support and a trend to improved survival.
\end{abstract}

Palabras clave

Trasplante cardiaco, Registro, Supervivencia

Abreviaturas

ECMO, RETC

Keywords

Heart transplant, Registry, Survival 


\section{INTRODUCCIÓN}

El trasplante cardiaco es actualmente, en ausencia de contraindicaciones, la terapia de elección para los pacientes con insuficiencia cardiaca y una limitación clínica avanzada a pesar de un tratamiento óptimo, médico y con dispositivos. En 2016 se realizaron en el mundo más de 7.000 trasplantes cardiacos, un tercio de ellos en Europa ${ }^{1}$. El mantenimiento de registros clínicos, sobre todo si son exhaustivos como el Registro Español de Trasplante Cardiaco (RETC), constituye una herramienta de primer orden para la mejora de la calidad de la asistencia y la investigación clínica en enfermedades o procedimientos de prevalencia limitada, como es el trasplante cardiaco.

En el presente informe anual se actualiza la actividad del RETC con los datos concernientes al año 2017.

\section{MÉTODOS}

\section{Pacientes y procedimientos}

Se analizan los datos relativos a las características clínicas de receptores y donantes, procedimiento quirúrgico, inmunosupresión y resultados de mortalidad en los 18 programas de trasplante cardiaco activos en España (tabla 1). Seis centros (2 de ellos en exclusiva) trasplantan a pacientes pediátricos y 2 centros realizan trasplantes combinados de corazón-pulmón. El número de procedimientos realizados desde el principio de la actividad se resume en la figura 1 . Desde 1984 se han realizado 8.173 trasplantes. Los tipos de procedimiento de toda la serie se resumen en la tabla 2.

Tabla 1. Centros participantes (por orden de realización del primer trasplante) en el Registro Español de Trasplante Cardiaco (1984-2017)

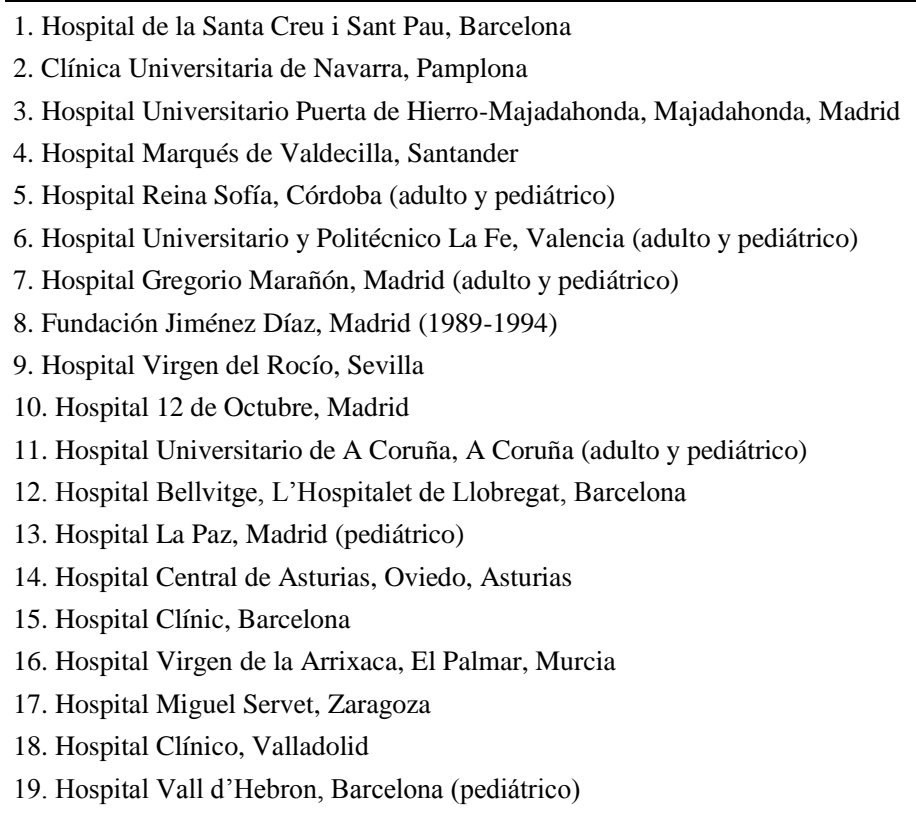




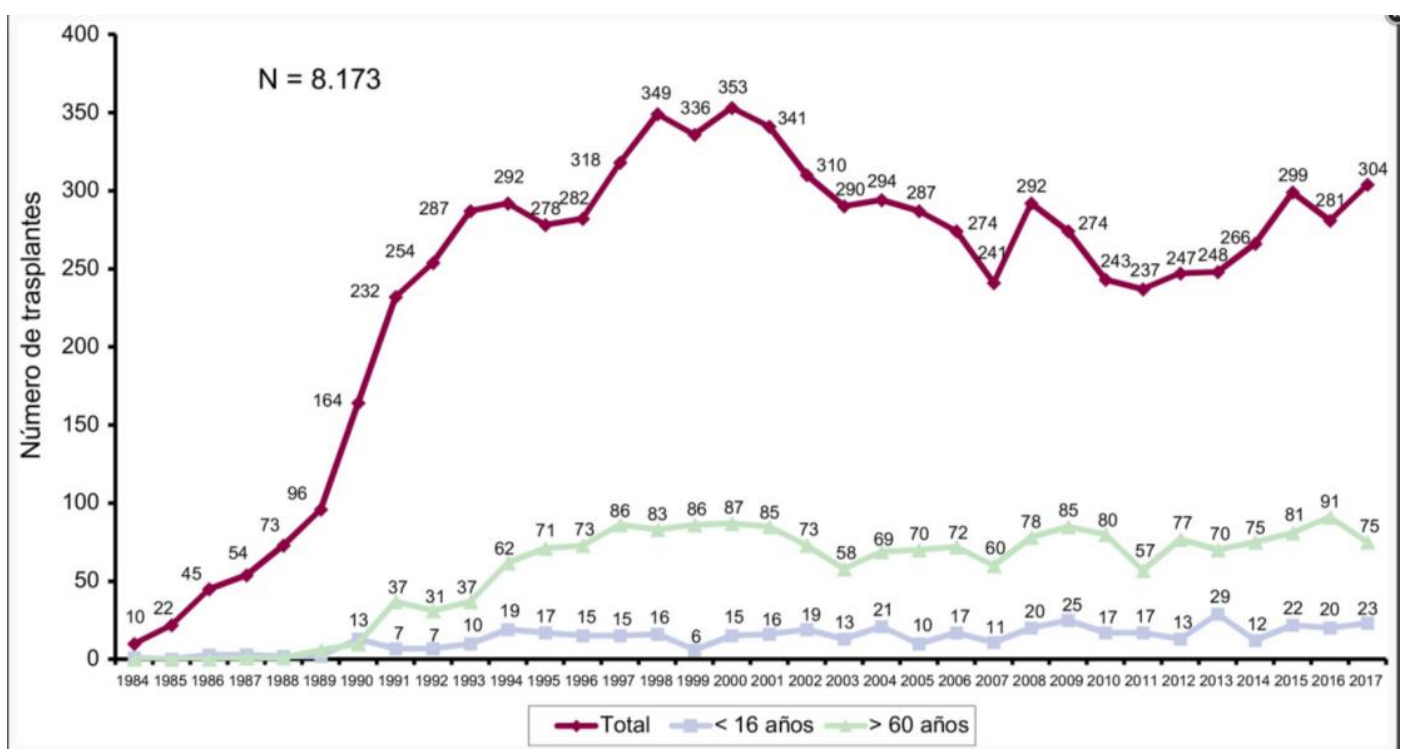

Figura 1. Número anual de trasplantes (1984-2017), total y por grupos de edad.

Tabla 2. Registro Español de Trasplante Cardiaco (1984-2017). Tipo de procedimiento

\begin{tabular}{lcc}
\hline Procedimiento & 2017 & 1984-2017 \\
\hline Trasplante cardiaco de novo & 295 & 7.806 \\
Retrasplante & 5 & 193 \\
$\quad$ Retrasplante combinado & 0 & $6^{\mathrm{a}}$ \\
Trasplantes combinados & 4 & 162 \\
$\quad$ Corazón-pulmón & 3 & 81 \\
Corazón-riñón & 0 & $70^{\mathrm{b}}$ \\
$\quad$ Corazón-hígado & 1 & 11 \\
Total & 304 & 8.161 \\
& \\
\hline \multicolumn{2}{c}{ a Todos los casos de trasplante renal. } \\
&
\end{tabular}

En el presente informe se analizan los resultados concernientes a los últimos 10 años (20082017). La evolución temporal de los resultados en este periodo se analiza atendiendo a tramos trianuales (2008-2010, 2011-2013, 2014-2016). En algunas variables, como el porcentaje de trasplante urgente, los tipos de asistencia circulatoria y la edad del donante, el análisis se realiza por año de trasplante.

En lo concerniente a la estructura de la base de datos, la recogida de los datos, el tratamiento informático, la auditoría y la política de protección de datos del RETC, se remite al lector a publicaciones previas ${ }^{2}$. Se ha intentado mantener las cifras de las distintas estadísticas de años anteriores a 2017 de manera coherente con trabajos previos. Puede haber pequeñas variaciones del orden de decimales debidas al proceso de actualización continua de la base de datos del registro. Sin embargo, debido a dicha actualización, cambios numéricos mayores que no afectan 
significativamente a la tendencia en las proporciones pueden apreciarse en la figura 2, que muestra el porcentaje relativo del tipo de asistencia circulatoria antes del trasplante.

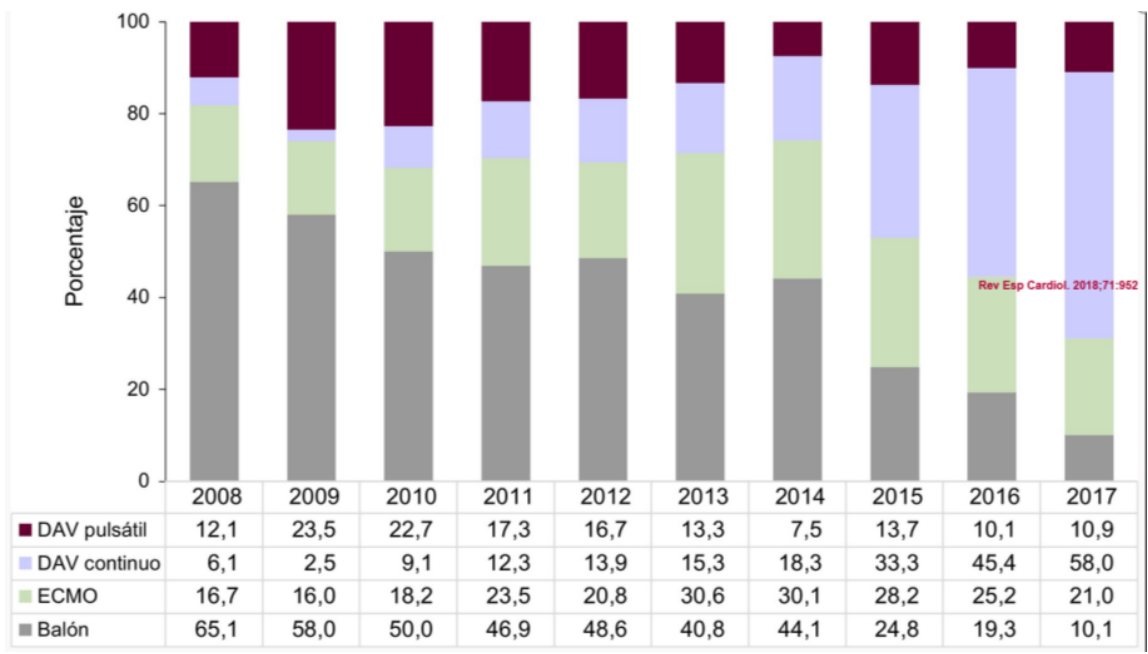

Figura 2. Distribución del tipo de asistencia circulatoria previa al trasplante, por años (2008-2017). DAV: dispositivo de asistencia ventricular; ECMO: oxigenador extracorpóreo de membrana.

\section{Análisis estadístico}

La variables continuas y categóricas se resumen como media \pm desviación estándar y porcentajes respectivamente. Las diferencias entre grupos se analizan mediante un test no paramétrico para la tendencia temporal (tau de Kendall) en el caso de variables categóricas y un ANOVA (análisis de la varianza) con ajuste polinómico para las variables continuas. Las curvas de supervivencia se calculan por el método de Kaplan-Meier y la comparación entre ellas, mediante log-rank test. Se consideran diferencias significativas las comparaciones con valor de $\mathrm{p}<0,05$.

\section{RESULTADOS}

\section{Características de los receptores}

Las principales características del receptor por trienios desde 2008 y en 2017 se resumen en la tabla 3. En 2017 se realizaron 304 trasplantes, 23 de ellos (7,6\%) a receptores menores de 16 años. Aproximadamente 3 de cada 4 fueron en varones, y la media de edad, 48,5 (intervalo, 0,05-73,0) años. Excluyendo a los pacientes pediátricos, la media de edad del receptor fue 51,8 años. La mayoría de los procedimientos fueron primeros trasplantes cardiacos aislados (97\%), y los retrasplantes y el trasplante combinado (fundamentalmente cardiopulmonar y cardiorrenal) fueron menos de un 3\% del total. Estas cifras se mantienen aproximadamente constantes desde 2008. 
Tabla 3. Características del receptor en el Registro Español de Trasplante Cardiaco (2008-2017)

\begin{tabular}{|c|c|c|c|c|c|}
\hline & $\begin{array}{c}2008-2010 \\
(n=807)\end{array}$ & $\begin{array}{c}2011-2013 \\
(n=732)\end{array}$ & $\begin{array}{c}2014-2016 \\
(\mathrm{n}=846)\end{array}$ & $\begin{array}{c}\mathrm{p} \mathrm{de} \\
\text { tendencia }\end{array}$ & $\begin{array}{c}2017 \\
(\mathrm{n}=304)\end{array}$ \\
\hline Edad (años) & $49,8 \pm 17,1$ & $49,1 \pm 17,1$ & $49,7 \pm 16,6$ & 0,9 & $48,5 \pm 16,6$ \\
\hline$<16$ años & 7,7 & 8,1 & 6,4 & 0,29 & 7,6 \\
\hline$>60$ años & 30,1 & 27,7 & 29,2 & 0,69 & 24,7 \\
\hline Varones & 73,0 & 74,3 & 75,4 & 0,26 & 72,4 \\
\hline IMC & $25,0 \pm 4,7$ & $24,6 \pm 4,8$ & $24,6 \pm 4,5$ & 0,11 & $25,0 \pm 5,1$ \\
\hline Etiología de base & & & & 0,88 & \\
\hline Dilatada no isquémica & 35,9 & 35,8 & 37,1 & & 38,2 \\
\hline Isquémica & 37,8 & 35,5 & 37,0 & & 31,3 \\
\hline Valvular & 6,9 & 6,3 & 4,0 & & 3,5 \\
\hline Otras & 19,3 & 22,4 & 21,9 & & 27,0 \\
\hline RVP (UW) & $2,5 \pm 1,7$ & $2,1 \pm 1,2$ & $2,2 \pm 1,3$ & 0,001 & $2,1 \pm 1,2$ \\
\hline Creatinina $>2 \mathrm{mg} / \mathrm{dl}$ & 5,6 & 5,0 & 6,0 & 0,71 & 6,6 \\
\hline Bilirrubina > $2 \mathrm{mg} / \mathrm{dl}$ & 15,4 & 15,8 & 16,8 & 0,48 & 19,6 \\
\hline Diabetes insulinodependiente & 15,6 & 19,4 & 23,1 & $<0,001$ & 22,6 \\
\hline EPOC moderada-grave & 9,3 & 8,7 & 11,7 & 0,1 & 9,6 \\
\hline Infección previa & 14,0 & 14,5 & 15,7 & 0,31 & 15,8 \\
\hline Cirugía cardiaca previa & 27,0 & 32,8 & 32,1 & 0,025 & 36,6 \\
\hline Tipo de trasplante & & & & 0,85 & \\
\hline Aislado & 96,2 & 95,8 & 96,3 & & 97,0 \\
\hline Retrasplante cardiaco & $1,6^{*}$ & 2,2 & 1,8 & & 1,6 \\
\hline Combinado & 2,1 & 2,0 & 1,9 & & 1,3 \\
\hline Corazón-pulmón & 1,1 & 0,9 & 1,0 & & 1 \\
\hline Corazón-riñón & $0,7^{*}$ & 0,9 & 0,7 & & - \\
\hline Corazón-hígado & 0,2 & 0,1 & 0,2 & & 0,3 \\
\hline $\begin{array}{l}\text { Ventilación mecánica antes del } \\
\text { trasplante }\end{array}$ & 18,4 & 15,8 & 14,6 & 0,04 & 11,8 \\
\hline Trasplante urgente & 34,3 & 41,1 & 46,3 & $<0,001$ & 44,4 \\
\hline $\begin{array}{l}\text { Asistencia circulatoria antes del } \\
\text { trasplante }\end{array}$ & & & & $<0,001$ & \\
\hline No & 73,6 & 65,7 & 61,1 & & 60,9 \\
\hline Balón de contrapulsación & 15,2 & 15,4 & 11,0 & & 3,9 \\
\hline ECMO & 4,5 & 8,7 & 10,8 & & 8,2 \\
\hline Asistencia ventricular & 6,7 & 10,1 & 17,1 & & 27,0 \\
\hline
\end{tabular}

ECMO: oxigenador extracorpóreo de membrana; EPOC: enfermedad pulmonar obstructiva crónica; IMC: índice de masa corpora RVP: resistencia vascular pulmonar. Los datos expresan porcentaje o media \pm desviación estándar.

* Un paciente con retrasplante cardiaco combinado con trasplante renal.

Desde 2008, se aprecia una tendencia temporal estadísticamente significativa a unas menores resistencias vasculares pulmonares $(\mathrm{p}=0,001)$, un mayor porcentaje de pacientes diabéticos $(\mathrm{p}<0,001)$, un mayor porcentaje de cirugía cardiaca previa al trasplante $(\mathrm{p}=0,025)$ y un menor porcentaje de ventilación mecánica en el momento del trasplante $(p=0,04)$. Se aprecia una tendencia no significativa a más receptores con enfermedad pulmonar obstructiva $(\mathrm{p}=0,10)$. 
En 2017 el 44\% de los procedimientos se realizaron con carácter de urgencia (figura 3). El $39,1 \%$ de los trasplantes fueron a receptores con algún dispositivo de asistencia circulatoria. Respecto a años previos, se ha observado un incremento del uso de dispositivos de asistencia ventricular de flujo continuo, a expensas de una marcada disminución del balón de contrapulsación, mientras que se ha mantenido estable el uso de oxigenadores extracorpóreos de membrana (ECMO) y asistencias ventriculares de flujo pulsátil (figura 2).

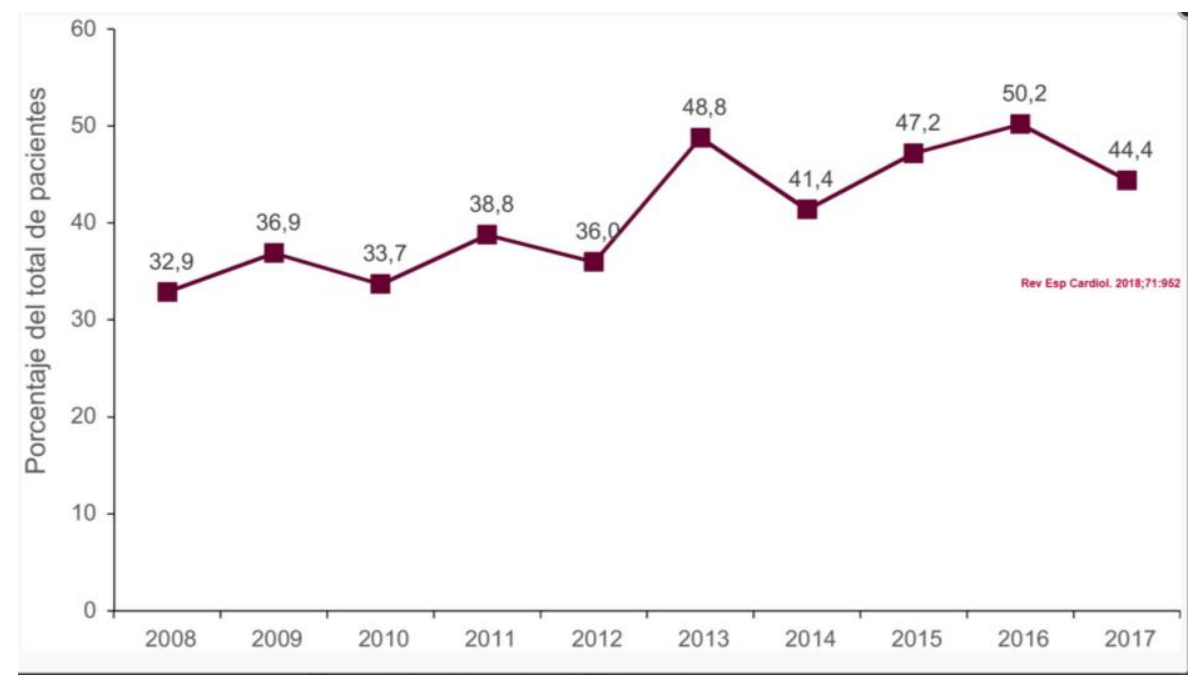

Figura 3. Porcentaje anual de trasplantes urgentes sobre la población total (2008-2017).

\section{Características de los donantes y tiempos de isquemia}

Las características de los donantes por periodo y en 2017 se resumen en la tabla 4. En 2017 continúan aumentando la media de edad de los donantes y el porcentaje de donantes mayores de 45 años, que han llegado casi al $60 \%$ del total (figura 4). Asimismo, siguen aumentando los porcentajes de donantes fallecidos por accidente cerebrovascular $(54,9 \%)$, en detrimento del de los fallecidos por traumatismo $(17,4 \%)$, y los donantes con parada cardiaca previa a la donación. Por el contrario, el tiempo de isquemia fría disminuye ligeramente en 2017, a expensas de la disminución del grupo con tiempos $>4 \mathrm{~h}(25,3 \%)$ y del aumento del grupo con tiempos $<2 \mathrm{~h}$. 
Tabla 4. Características de los donantes y tiempos de isquemia en el Registro Español de Trasplante Cardiaco (2008-2017)

\begin{tabular}{|c|c|c|c|c|c|}
\hline & $\begin{array}{c}2008-2010 \\
(\mathrm{n}=807)\end{array}$ & $\begin{array}{l}2011-2013 \\
(\mathrm{n}=732)\end{array}$ & $\begin{array}{c}2014-2016 \\
(\mathrm{n}=846)\end{array}$ & $\begin{array}{c}\mathrm{p} \mathrm{de} \\
\text { tendencia }\end{array}$ & $\begin{array}{c}2017 \\
(n=304)\end{array}$ \\
\hline $\operatorname{Edad}(a \tilde{n} o s)$ & $37,4 \pm 14,4$ & $39,8 \pm 15,6$ & $43,3 \pm 14,4$ & $<0,001$ & $44,7 \pm 14,0$ \\
\hline Edad $>45$ años & 35,2 & 41,8 & 54,1 & $<0,001$ & 59,9 \\
\hline Varones & 66,8 & 61,2 & 59 & 0,001 & 60,9 \\
\hline Donante mujer-receptor varón & 18,3 & 23,4 & 24,8 & 0,001 & 23,0 \\
\hline Peso (kg) & $72,7 \pm 18,1$ & $72,6 \pm 18,6$ & $74,6 \pm 17,9$ & 0,03 & $74,7 \pm 17,2$ \\
\hline Peso receptor/donante & $0,94 \pm 0,2$ & $0,94 \pm 0,2$ & $0,93 \pm 0,2$ & 0,14 & $0,96 \pm 0,2$ \\
\hline Peso receptor/donante $>1,2$ & 7,6 & 8,1 & 6,3 & 0,27 & 10,9 \\
\hline Peso receptor/donante $<0,8$ & 20,0 & 21,1 & 21,8 & 0,38 & 21,1 \\
\hline Causa de la muerte & & & & 0,016 & \\
\hline Traumatismo & 30,6 & 30,5 & 23,2 & & 17,4 \\
\hline Cerebrovascular & 44,1 & 46,4 & 50,7 & & 54,9 \\
\hline Otras & 25,3 & 23,1 & 26,1 & & 27,6 \\
\hline $\begin{array}{l}\text { Parada cardiaca antes del } \\
\text { trasplante }^{\text {a }}\end{array}$ & 10,1 & 12,4 & 16,8 & $<0,001$ & 19,4 \\
\hline $\begin{array}{l}\text { Ecocardiograma previo a la } \\
\text { donación }^{\mathrm{b}}\end{array}$ & & & & 0,09 & \\
\hline No realizado & 3,3 & 3,0 & 1,0 & & 1,6 \\
\hline Normal & 93,8 & 94 & 96,3 & & 95,6 \\
\hline Disfunción general leve & 2,1 & 3,0 & 2,7 & & 2,8 \\
\hline Tiempo de isquemia (min) & $212,4 \pm 64,3$ & $211,0 \pm 60,1$ & $197,7 \pm 72,2$ & $<0,001$ & $193,4 \pm 71,1$ \\
\hline$\leq 120 \mathrm{~min}$ & 9,8 & 8,9 & 16,3 & 0,001 & 18,8 \\
\hline $120-180 \mathrm{~min}$ & 21,8 & 19,4 & 22,6 & & 20,4 \\
\hline $180-240 \mathrm{~min}$ & 37,9 & 42,8 & 34,3 & & 35,5 \\
\hline$>240 \mathrm{~min}$ & 30,5 & 28,9 & 26,8 & & 25,3 \\
\hline
\end{tabular}

Los valores expresan porcentaje o media \pm desviación estándar.

a Sobre 2.129 trasplantes.

${ }^{\mathrm{b}}$ Sobre 2.066 trasplantes.

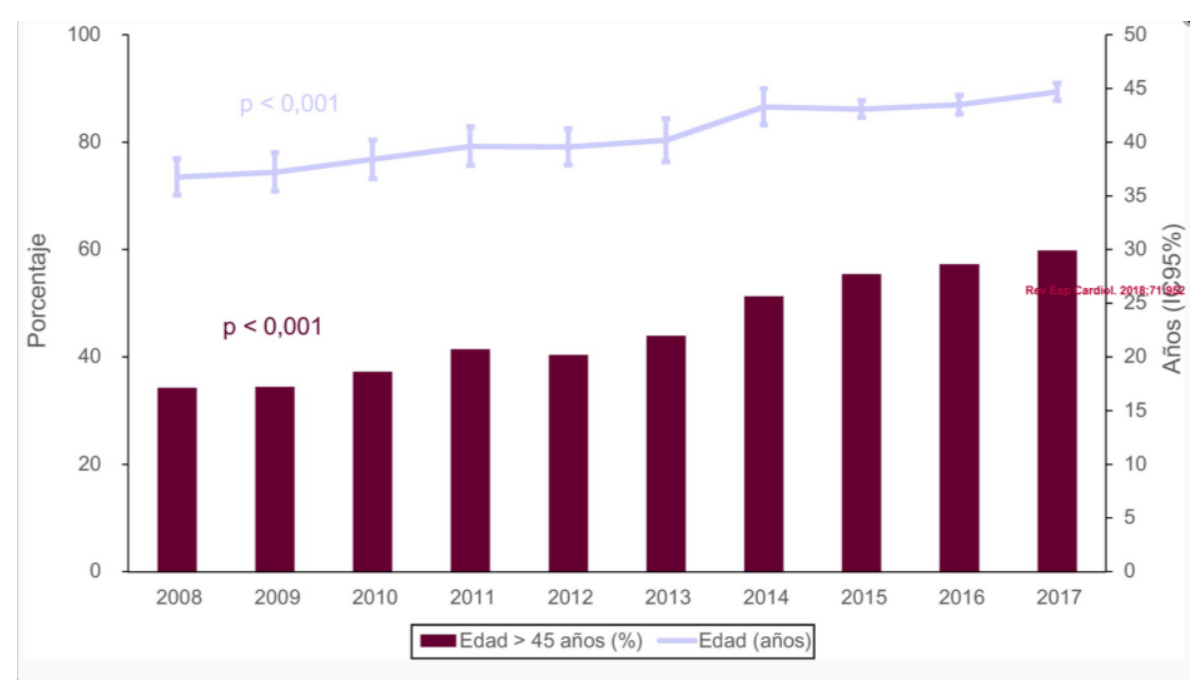

Figura 4. Evolución anual de la edad del donante y el porcentaje de donantes con edad > 45 años (2008-2017). DAV: dispositivo de asistencia ventricular; ECMO: oxigenador extracorpóreo de membrana; IC95\%: intervalo de confianza del $95 \%$. 


\section{Inmunosupresión}

Los fármacos utilizados como inmunosupresión de inicio en el periodo de estudio se resumen en la tabla 5. En 2017, tal como venía ocurriendo en años previos, la inmunosupresión inicial se compuso mayoritariamente de tacrolimus $(90,5 \%)$, micofenolato (y, en medida mucho menor, ácido micofenólico) $(96,6 \%)$ y corticoides (98\%). En aproximadamente el $85 \%$ de los casos, se utilizó también terapia de inducción basada en anticuerpos, mayormente con basiliximab $(76,1 \%)$.

Tabla 5. Inmunosupresión de inicio en el Registro Español de Trasplante Cardiaco (2008-2017)

\begin{tabular}{|c|c|c|c|c|c|}
\hline & $\begin{array}{c}2008-2010 \\
(n=807)\end{array}$ & $\begin{array}{c}2011-2013 \\
(\mathrm{n}=732)\end{array}$ & $\begin{array}{c}2014-2016 \\
(n=846)\end{array}$ & $\begin{array}{c}\mathrm{p} \mathrm{de} \\
\text { tendencia }\end{array}$ & $\begin{array}{c}2017 \\
(\mathrm{n}=304)\end{array}$ \\
\hline \multicolumn{6}{|c|}{ Inhibidores de calcineurina (\%) } \\
\hline Ciclosporina & 35,5 & 23,6 & 8,0 & $<0,001$ & 5,8 \\
\hline Tacrolimus & 59,5 & 72,3 & 89,2 & $<0,001$ & 90,5 \\
\hline \multicolumn{6}{|l|}{ Antiproliferativos (\%) } \\
\hline $\begin{array}{l}\text { Micofenolato/ácido } \\
\text { micofenólico }\end{array}$ & 94,6 & 96,4 & 96,2 & 0,93 & 96,6 \\
\hline Azatioprina & 2,5 & 0,3 & 0,9 & 0,013 & 1,4 \\
\hline \multicolumn{6}{|l|}{ Inhibidores de m-TOR } \\
\hline Sirolimus & 0,4 & 0,5 & 0,3 & 0,58 & 1,2 \\
\hline Everolimus & 3,0 & 1,6 & 1,7 & 0,11 & 1,2 \\
\hline Corticoides & 97,8 & 97,5 & 98,0 & 0,78 & 98,0 \\
\hline Inducción & & & & $<0,01$ & \\
\hline No & 12,0 & 14,1 & 15,4 & & 15,9 \\
\hline ALG/ATG & 5,2 & 2,4 & 3,2 & & 5,0 \\
\hline Daclizumab & 14,8 & 0,4 & 0,2 & & 0,7 \\
\hline Basiliximab & 67,1 & 83,0 & 80,8 & & 76,1 \\
\hline Otros & 0,9 & 0,1 & 0,4 & & 2,3 \\
\hline
\end{tabular}

ALG: globulina antilinfocítica; ATG: globulina antitimocítica.

\section{Supervivencia}

La supervivencia en el periodo de estudio 2008-2017 se analiza en la figura 5. En comparación con la supervivencia, considerando toda la experiencia anterior a 2008, se observa una mejora estadísticamente significativa, que es achacable tanto a la supervivencia en el primer año como a la más tardía. La primera ha mejorado un promedio de 2,5 puntos porcentuales. Más allá del primer año, la tasa de atrición anual ha pasado del 2,2 al 1,6\%. En el periodo de estudio 2008-2016, se detecta una tendencia general a la mejora de la supervivencia a lo largo de la serie, que llega al borde de la significación $(\mathrm{p}=0,056)$ en la comparación entre los trienios 2014-2016 y 2008-2011 (figura 6). 


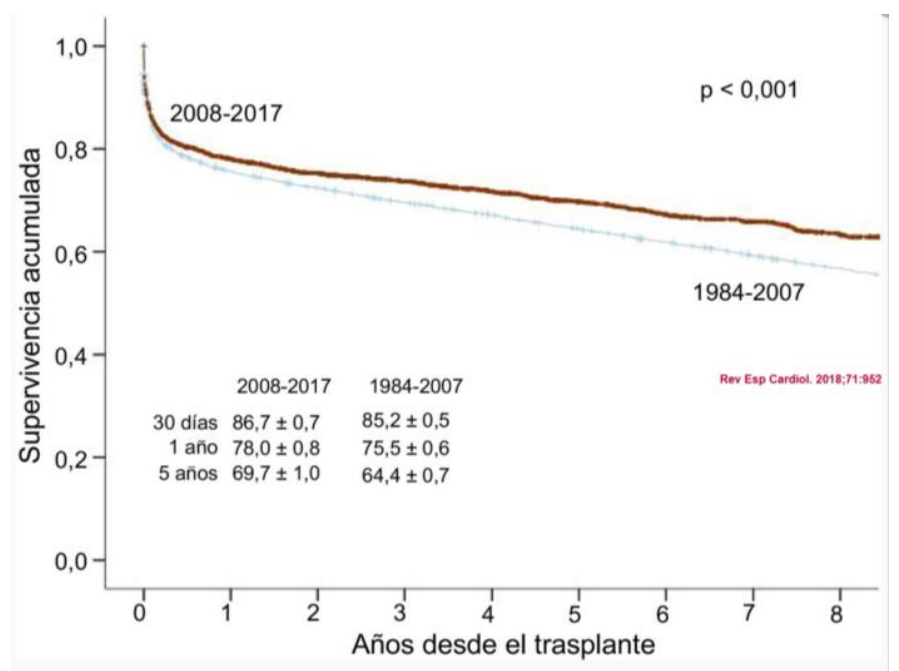

Figura 5. Comparación de las curvas de supervivencia entre los periodos 2008-2017 y 1984-2007.

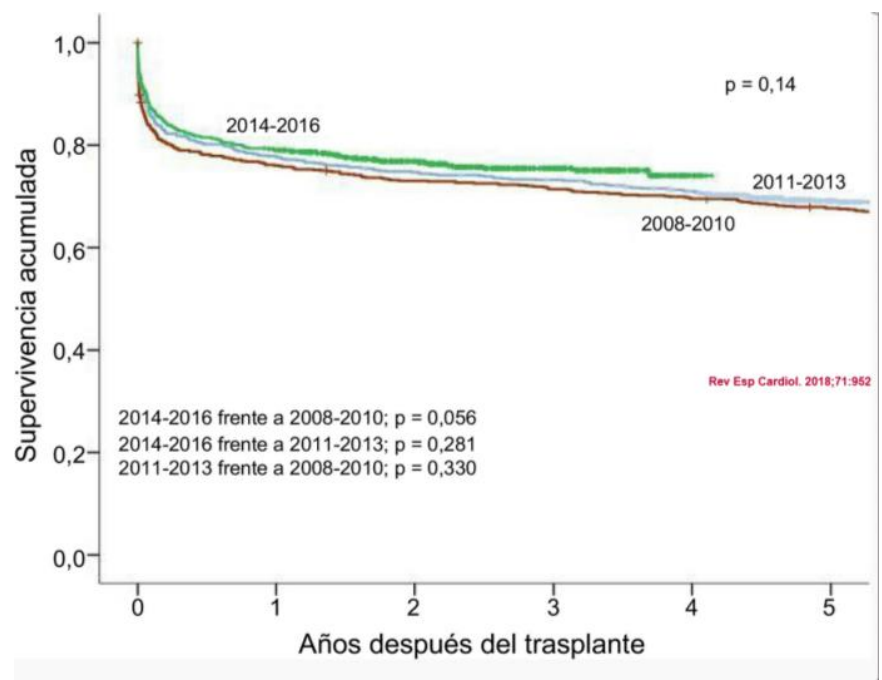

Figura 6. Comparación de las curvas de supervivencia del periodo 2008-2016 por trienios.

Los factores más destacables que afectan a la supervivencia durante el periodo de estudio son la edad del receptor y el tipo de asistencia circulatoria antes del trasplante (tabla 6). Así, con respecto a los receptores en edad pediátrica $(<16$ años), los pacientes mayores de 60 años en el momento del trasplante muestran un aumento de mortalidad del $70 \%(\mathrm{p}=0,001)$, mientras que los receptores de edad intermedia (16-60 años) tienen un riesgo $>30 \%(\mathrm{p}=0,07)$. El uso de ECMO previo al trasplante conlleva un exceso del $40 \%(\mathrm{p}=0,008)$ en el riesgo de mortalidad respecto a los pacientes trasplantados sin asistencia. Sin embargo, los resultados de los receptores portadores de balón de contrapulsación o dispositivos de asistencia ventricular son superponibles a los de los pacientes trasplantados sin asistencia (tabla 6). Para el periodo 2008-2017 no se encuentra que la edad del donante o el código de urgencia influyan en la supervivencia. 
Tabla 6. Análisis univariable de supervivencia según las características basales del receptor, el donante y el procedimiento (2008-2017)

\begin{tabular}{|c|c|c|c|}
\hline & HR (IC95\%) & $\mathrm{p}$ & $\begin{array}{c}\text { Supervivencia (años), } \\
\text { mediana (IC95\%) }\end{array}$ \\
\hline \multicolumn{4}{|l|}{ Edad del receptor } \\
\hline$<16$ años & 1 & & - \\
\hline $16-60$ años & $1,3(1,0-1,8)$ & 0,07 & - \\
\hline$>60$ años & $1,7(1,3-2,4)$ & 0,001 & $9,2(8,6-9,8)$ \\
\hline \multicolumn{4}{|l|}{ Tipo de trasplante } \\
\hline Trasplante aislado & 1 & & - \\
\hline Trasplante combinado & $1,5(1,0-2,3)$ & 0,06 & - \\
\hline Retrasplante & $1,4(0,9-2,2)$ & 0,15 & - \\
\hline \multicolumn{4}{|l|}{ Edad del donante } \\
\hline$\leq 45$ años & 1 & & $10,0(9,3-10,6)$ \\
\hline$>45$ años & $1,0(0,9-1,1)$ & 0,97 & $10,0(9,2-10,8)$ \\
\hline \multicolumn{4}{|l|}{ Código de urgencia } \\
\hline Electivo & 1 & & - \\
\hline Urgente & $1,1(1,0-1,3)$ & 0,11 & $10,0(9,4-10,7)$ \\
\hline \multicolumn{4}{|l|}{ Tipo de asistencia } \\
\hline Sin asistencia & 1 & & - \\
\hline Balón de contrapulsación & $1,0(0,8-1,3)$ & 0,65 & - \\
\hline ECMO & $1,4(1,1-1,8)$ & 0,008 & - \\
\hline Asistencia ventricular & $1,1(0,9-1,3)$ & 0,49 & - \\
\hline
\end{tabular}

ECMO: oxigenador extracorpóreo de membrana; HR: hazard ratio; IC95\%: intervalo de confianza del $95 \%$.

\section{Causas de fallecimiento}

El fallo primario del injerto es la causa de muerte más frecuente en el primer año tras el trasplante $(32,6 \%)$, particularmente el primer mes $(43,5 \%)$, seguido por la infección $(22,9 \%)$. Entre el primer y el quinto año tras el trasplante, las causas de muerte más frecuentes son la enfermedad vascular del injerto/muerte súbita $(27,8 \%)$ y la neoplasia (21,1\%) (figura 7$)$. En general, el rechazo agudo del injerto es la causa de muerte en el $8 \%$ de los casos, tasa que es casi el triple $(17,8 \%)$ entre el primer y el quinto año tras el trasplante que en el primer año $(6,1 \%)$. 


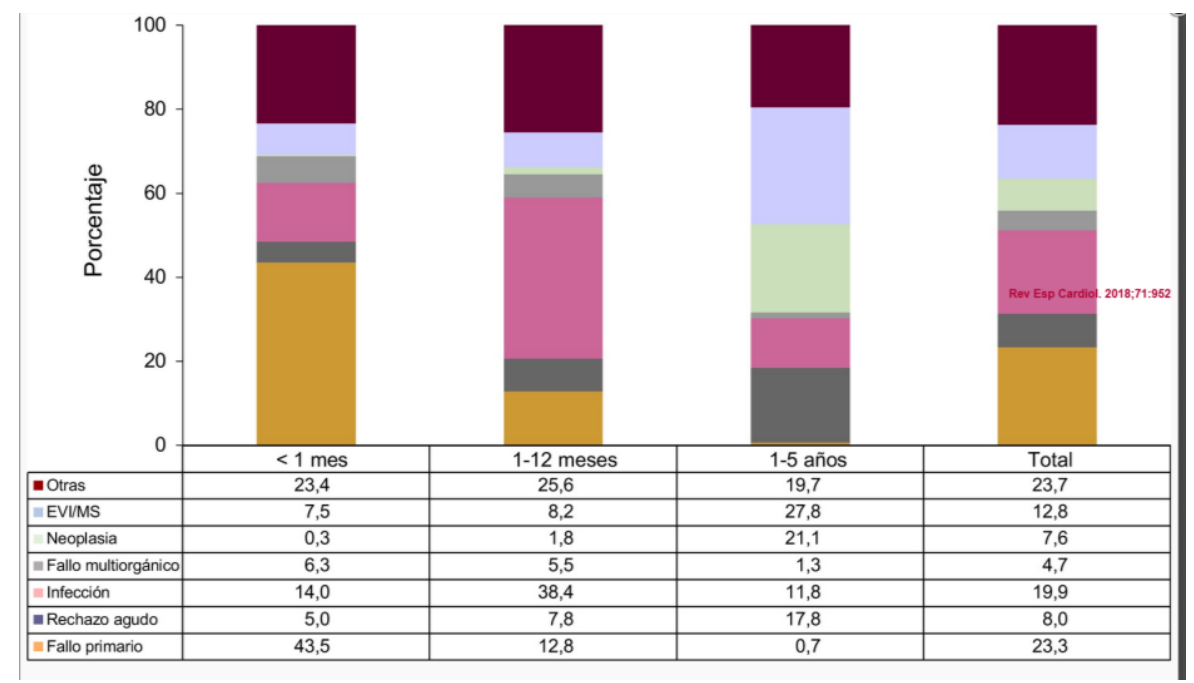

Figura 7. Causas de muerte principales según el tiempo transcurrido desde el trasplante en el periodo 2008-2017. EVI/MS: enfermedad vascular del injerto/muerte súbita.

Considerando la mortalidad en el primer año tras el trasplante, lapso completado prácticamente por todos los pacientes incluidos en el presente análisis, se observa un aumento significativo de la infección como causa de muerte a partir de 2011, y después permanece estable (figura 8). Por el contrario, se constata una disminución progresiva y estadísticamente significativa del fallo primario del injerto como causa de muerte en dicho periodo postrasplante. El rechazo muestra unas tasas de mortalidad estables a lo largo de la última década (figura 8).

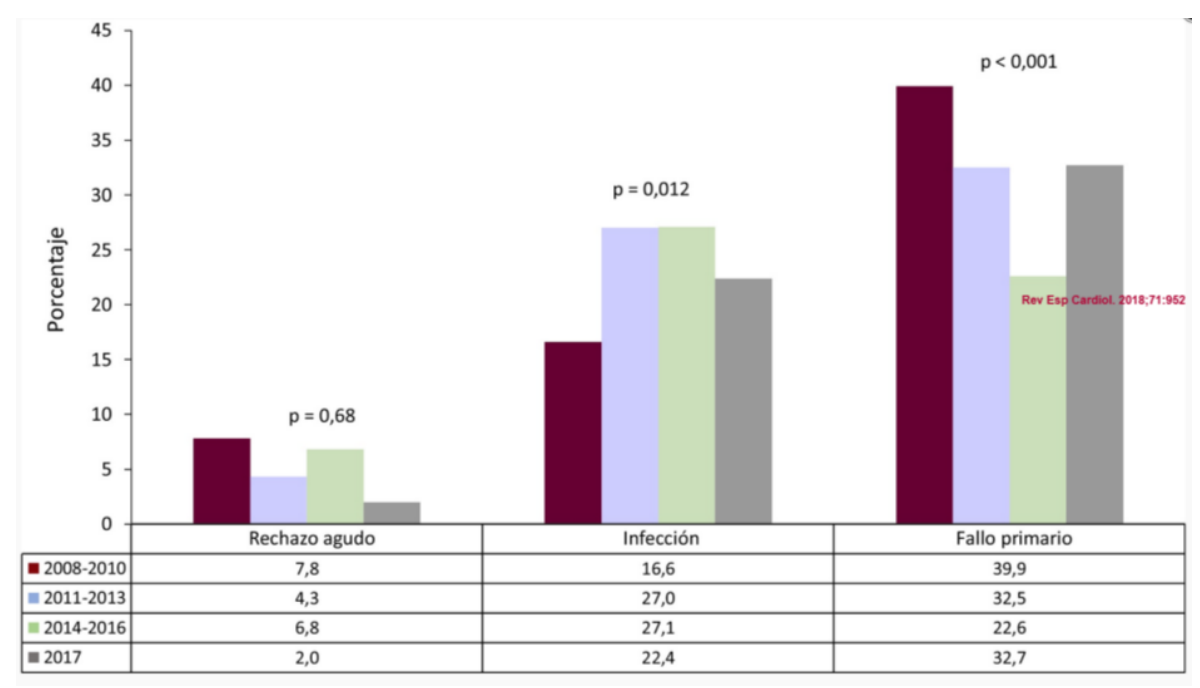

Figura 8. Evolución de las causas de muerte principales en el primer año postrasplante en el periodo 2008-2016, por trienios. El valor de p hace referencia a la significación de la tendencia entre trienios, excluyendo el año 2017. En 2017, solo 17 pacientes tenían un seguimiento $\geq 1$ año en el momento del cierre de la base de datos. 


\section{DISCUSIÓN}

La actividad trasplantadora se ha mantenido estable en España en los últimos años, entre 250 y 300 trasplantes anuales. Teniendo en cuenta las características contemporáneas de los donantes y que solo se llevan a cabo trasplantes de donantes en muerte cerebral, es probable que este número pueda estar muy cerca del techo de nuestra actividad. El uso de criterios expandidos en la aceptación de donantes, particularmente aquellos con muerte circulatoria, podría aumentar el número de donantes disponibles, tal como se ha observado en pequeñas experiencias en otros países $^{3}$. Asimismo, la disponibilidad de donantes podría incrementarse con la generalización del uso de coronariografía en los casos de donantes de más edad o con factores de riesgo cardiovascular, que constituyen el grueso de la donación actual en España ${ }^{4}$.

En 2017 se confirman y eventualmente se intensifican las tendencias observadas en la década previa. Además de la ya comentada utilización de donantes cada vez mayores, y hasta hace poco considerados «marginales», el aspecto más llamativo tal vez sea el cambio en la modalidad de asistencia circulatoria previa a la intervención en los trasplantes urgentes. En informes previos del RETC $^{2}$, ya se había constatado la deficiencia de los resultados en supervivencia a corto plazo de los pacientes trasplantados con asistencia previa con ECMO, en comparación con los intervenidos con asistencia ventricular. Estos hallazgos se confirmaron con una investigación más exhaustiva del RETC publicada recientemente ${ }^{5}$, y constituyen la base para la modificación de los criterios de inclusión en lista urgente de la Organización Nacional de Trasplantes a partir de junio de 2017. La estabilización clínica de los receptores asistidos con dispositivos de asistencia ventricular permite realizar el trasplante en una mejor condición médica y hemodinámica del paciente, lo cual incluye la disminución del requerimiento de ventilación mecánica ${ }^{6,7}$. De esta manera es posible conseguir una supervivencia similar a la alcanzada en los trasplantes electivos.

Los datos actuales mantienen la tendencia observada en informes previos hacia una mejora de los resultados del trasplante en España a lo largo de los años. Esta tendencia, aunque no significativa desde el punto de vista estadístico, probablemente como efecto del tamaño muestral, se observa incluso en los últimos 10 años. En este sentido, lo más llamativo es la disminución de la mortalidad precoz, que se ha conseguido fundamentalmente por la disminución progresiva de la muerte por fallo primario del injerto, junto con la estabilización de las muertes por infección y por rechazo agudo del injerto. Estos hallazgos pueden explicarse por la disminución del promedio de tiempo de isquemia, como factor preventivo del fallo primario, y por la amplia implantación de los programas de asistencia circulatoria, especialmente eficaz para el tratamiento de esta grave complicación, como factor terapéutico ${ }^{8}$.

\section{CONCLUSIONES}

La actividad de trasplante cardiaco en España está estabilizada entre 250 y 300 procedimientos al año. En 2017, se aprecia un aumento del uso de dispositivos de asistencia ventricular previo al trasplante y se confirma el uso de donantes de más edad. La supervivencia sigue mejorando de manera progresiva.

\section{CONFLICTO DE INTERESES}

F. González-Vílchez ha cooperado con presentaciones educativas para Novartis y ha recibido compensación por gastos de viaje por Pfizer y Bayer. M.G. Crespo-Leiro ha recibido una beca de CIBERCV, ha cooperado en presentaciones educativas con Novartis, Astellas, MSD y Abbott y ha recibido compensación por gastos de viaje de Novartis y Astellas. J. González-Costelo es consultor de Alnylam, Abbot, Pfizer y Novartis, ha impartido ponencias para Novartis y ha recibido compensación por gastos de viaje de Astellas y Servier. 


\section{ANEXO. COLABORADORES DEL REGISTRO ESPAÑOL DE TRASPLANTE CARDIACO 1984-2017}

\begin{tabular}{|c|c|}
\hline $\begin{array}{l}\text { Hospital Universitario Puerta de Hierro- } \\
\text { Majadahonda, Majadahonda, Madrid }\end{array}$ & Javier Segovia-Cubero, Manuel Gómez-Bueno, Francisco Hernández-Pérez \\
\hline $\begin{array}{l}\text { Hospital Universitario y Politécnico La Fe, } \\
\text { Valencia }\end{array}$ & $\begin{array}{l}\text { Soledad Martínez-Penades, Mónica Cebrián-Pinar, Raquel López-Vilella, } \\
\text { Ignacio Sánchez-Lázaro, Luis Martínez-Dolz }\end{array}$ \\
\hline $\begin{array}{l}\text { Complejo Hospitalario Universitario de } \\
\text { A Coruña, A Coruña }\end{array}$ & $\begin{array}{l}\text { Maria J Paniagua-Martín, Eduardo Barge-Caballero, Gonzalo Barge- } \\
\text { Caballero, David Couto-Mallón }\end{array}$ \\
\hline Hospital Universitario Reina Sofía, Córdoba & $\begin{array}{l}\text { Amador López-Granados, Carmen Segura-Saintgerons, Dolores Mesa, } \\
\text { Martín Ruiz, Elías Romo, Francisco Carrasco, José López-Aguilera }\end{array}$ \\
\hline $\begin{array}{l}\text { Hospital Universitario Marqués de Valdecilla, } \\
\text { Santander }\end{array}$ & $\begin{array}{l}\text { Manuel Cobo, Miguel Llano-Cardenal, José A. Vázquez de Prada, Francisco } \\
\text { Nistal-Herrera }\end{array}$ \\
\hline Hospital Gregorio Marañón (adultos), Madrid & $\begin{array}{l}\text { María Jesús Valero, Juan Fernández-Yáñez, Paula Navas, Carlos Ortiz, } \\
\text { Adolfo Villa, Eduardo Zataraín, Manuel Martínez-Sellés }\end{array}$ \\
\hline Hospital Universitario 12 de Octubre, Madrid & María Dolores García-Cosío, Laura Morán-Fernández, Zorba Blázquez \\
\hline $\begin{array}{l}\text { Hospital de la Santa Creu i Sant Pau, } \\
\text { Barcelona }\end{array}$ & $\begin{array}{l}\text { Eulàlia Roig-Minguell, Vicens Brossa-Loidi, Sonia Mirabet-Pérez, Laura } \\
\text { López-López }\end{array}$ \\
\hline $\begin{array}{l}\text { Hospital Universitario Virgen del Rocío, } \\
\text { Sevilla }\end{array}$ & Ernesto Lage-Gallé, Diego Rangel-Sousa \\
\hline $\begin{array}{l}\text { Hospital Universitario de Bellvitge, } \\
\text { L'Hospitalet de Llobregat, Barcelona }\end{array}$ & Nicolás Manito-Lorite, Carles Díez-López, Josep Roca-Elías \\
\hline Clínica Universitaria de Navarra, Pamplona & Gregorio Rábago-Aracil \\
\hline Hospital Clínic Universitari, Barcelona & María Ángeles Castel, Marta Farrero, Ana García-Álvarez \\
\hline $\begin{array}{l}\text { Hospital Universitario Central de Asturias, } \\
\text { Oviedo }\end{array}$ & $\begin{array}{l}\text { José Luis Lambert-Rodríguez, Beatriz Díaz-Molina, María José Bernardo- } \\
\text { Rodríguez }\end{array}$ \\
\hline $\begin{array}{l}\text { Hospital Universitario Gregorio Marañón } \\
\text { (infantil), Madrid }\end{array}$ & Manuela Camino-López, Juan Miguel Gil-Jaurena, Nuria Gil-Villanueva \\
\hline $\begin{array}{l}\text { Hospital Universitario Virgen de la Arrixaca, } \\
\text { El Palmar, Murcia }\end{array}$ & Iris Garrido-Bravo \\
\hline $\begin{array}{l}\text { Hospital Universitario Miguel Servet, } \\
\text { Zaragoza }\end{array}$ & Teresa Blasco-Peiró, Ana Pórtoles-Ocampo, Marisa Sanz-Julve \\
\hline Clínico Universitario, Valladolid & Luis de la Fuente-Galán, Javier Tobar-Ruiz, Ana María Correa-Fernández \\
\hline Hospital Universitario La Paz, Madrid & $\begin{array}{l}\text { Luis García-Guereta Silva, Álvaro González-Rocafort, Carlos Labradero-de } \\
\text { Lera, Luz Polo- López }\end{array}$ \\
\hline $\begin{array}{l}\text { Hospital Universitario Vall d'Hebron, } \\
\text { Barcelona }\end{array}$ & Dimpna C. Albert-Brotons, Ferrán Gran-Ipiña, Raúl Abella-Antón \\
\hline
\end{tabular}

\section{BIBLIOGRAFÍA}

1. Newsletter Transplant. International figures of donation and transplantation 2016. Disponible en http://www.ont.es/publicaciones/Documents/NEWSLETTER\%202017_baja\%20(2).pdf. Citado $18 \mathrm{Jul} 2018$.

2. González-Vílchez F, Gómez-Bueno M, Almelnar-Bonet L, et al. Registro Español de Trasplante Cardiaco. XXVIII Informe Oficial de la Sección de Insuficiencia Cardiaca de la Sociedad Española de Cardiología (1984-2016). Rev Esp Cardiol. 2017;70:1098-109.

3. Messer SJ, Axell RG, Colah S, et al. Functional assessment and transplantation of the donor heart after circulatory death. J Heart Lung Transpl. 2016;35:1443-52.

4. Organización Nacional de Trasplantes. Memoria de Actividad. ONT 2016. Disponible en: http://www.ont.es/infesp/Memorias/Memoria\%20Donaci\%C3\%B3n\%202016.pdf. Citado 25 May 2018.

5. Barge-Caballero E, Almenar-Bonet L, Gonzalez-Vilchez F, et al. Clinical outcomes of temporary mechanical circulatory support as a direct bridge to heart transplantation: a nationwide Spanish registry. Eur J Heart Fail. 2018;20:178-86.

6. Sánchez-Enrique C, Jorde UP, González-Costelo J. Trasplante cardiaco y soporte circulatorio mecánico para pacientes con insuficiencia cardiaca avanzada. Rev Esp Cardiol. 2017;70:371-81. 
7. Gómez Bueno M, Segovia-Cubero J, Serrano Fiz S, et al. Experiencia con una asistencia ventricular pulsátil de larga duración como puente al trasplante cardiaco en adultos. Rev Esp Cardiol. 2017;70:727-35.

8. Phan K, Luc JG, Xu J, et al. Utilization and outcomes of temporary mechanical circulatory support for graft dysfunction after heart transplantation. ASAIO J. 2017;63:695-703. 